\title{
Retrieval of sea surface velocities using sequential Ocean Colour Monitor (OCM) data
}

\author{
J S Prasad ${ }^{1, *}$, A S Rajawat ${ }^{1}$, Yaswant Pradhan ${ }^{1}$, O S Chauhan ${ }^{2}$ and S R Nayak \\ * Presently at Applied Geophysical Laboratories, Department of Geophysics, University of Houston, Texas 7r204, \\ $U S A$ \\ ${ }^{1}$ Marine and Water Resources Group, Remote Sensing Applications Area, Space Applications Centre (ISRO), \\ Ahmedabad 380 015, India. \\ ${ }^{2}$ Geological Oceanography Division, National Institute of Oceanography, Dona Paula, Goa 403 004, India.
}

The Indian remote sensing satellite, IRS-P4 (Oceansat-I) launched on May 26th, 1999 carried two sensors on board, i.e., the Ocean Colour Monitor (OCM) and the Multi-frequency Scanning Microwave Radiometer (MSMR) dedicated for oceanographic research. Sequential data of IRS-P4 OCM has been analysed over parts of both east and west coast of India and a methodology to retrieve sea surface current velocities has been applied. The method is based on matching suspended sediment dispersion patterns, in sequential two time lapsed images. The pattern matching is performed on a pair of atmospherically corrected and geo-referenced sequential images by Maximum Cross-Correlation (MCC) technique. The MCC technique involves computing matrices of cross-correlation coefficients and identifying correlation peaks. The movement of the pattern can be calculated knowing the displacement of windows required to match patterns in successive images. The technique provides actual flow during a specified period by integrating both tidal and wind influences. The current velocities retrieved were compared with synchronous data collected along the east coast during the GSI cruise ST-133 of R.V. Samudra Kaustubh in January 2000. The current data were measured using the ocean current meter supplied by the Environmental Measurement and CONtrol (EMCON), Kochi available with the Geological Survey of India, Marine Wing. This current meter can measure direction and magnitude with an accuracy of $\pm 5^{\circ}$ and $2 \%$ respectively. The measurement accuracies with coefficient of determination $\left(R^{2}\right)$ of 0.99 , for both magnitude $\left(\mathrm{cm} . \mathrm{s}^{-1}\right)$ and direction (deg.) were achieved.

\section{Introduction}

The Indian remote sensing satellite (IRS-P4), also known as the OCEANSAT-1, was launched on May 26th, 1999 by the Indian Space Research Organisation (ISRO). The satellite carried two oceanographic payloads i.e., the Ocean Colour Monitor (OCM) and the Microwave Scanning Multi-frequency Radiometer (MSMR). The first payload of OCM is designed to measure ocean colour, the spectral variation of water leaving radiance that can be related to concentration of phyto- plankton pigments, suspended sediments, coloured dissolved organic matter i.e., yellow substance or gelbstoff and aerosols. This paper focuses on retrieving advective vectors using sediments as a tracer from the suspended sediment maps derived from the OCM data. The method is based on matching suspended sediment dispersion patterns, in sequential two-time lapsed images. The pattern matching is performed on a pair of atmospherically corrected and geo-referenced sequential images by Maximum Cross-Correlation (MCC) technique. The work follows the technique developed by many

Keywords. IRS-P4 OCM; suspended sediment concentration; advective velocity; maximum cross-correlation; coregistration. 
investigators (La Violette 1984; Vastano and Borders 1984; Emery et al 1986; Kelly 1989; Garcia and Robinson 1989; Wu et al 1992) and has been applied on IRS-P4 OCM derived suspended sediment maps for the Indian region. The velocities retrieved are time-averaged velocities between the data sets used. This methodology retrieves velocities in terms of rate of transport of sediments. The retrieved velocities were validated using synchronous data collected along the east coast during a cruise (ST-133) onboard R.V. Samudra Kaustubh in January 2000. It is suggested that the use of this technique will find useful applications in providing inputs to hydrodynamic modelling of coastal processes such as computation of alongshore transport, pollutants dispersion rates, siltation, etc.

\section{Materials and methods}

\subsection{Selection of sequential data}

As part of the IRS-P4 OCM validation programme, synchronous sea truth data with the satellite pass were collected in the northern Bay of Bengal during January 13th - 25th, 2000 onboard R. V. Samudra Kaustubh Cruise No ST-133, a vessel owned by the Geological Survey of India (GSI), Kolkata. IRS-P4 OCM data of the same period were selected for this study. OCM collects data in eight spectral channels $(402-422,433-453,480-500,500-520$, $545-565,660-680,745-785,845-885 \mathrm{~nm})$ with spatial resolution of $360 \mathrm{~m}$, every alternate day for the same region at local time around 12 noon with radiometric resolution of 12 bits. Each OCM scene covers $1420 \mathrm{~km}$ by $1420 \mathrm{~km}$ ground area. Sediment plumes off Mahanadi delta provided persistent features which were useful for implementing the technique.

\subsection{Atmospheric correction}

It is well known that in the case of ocean remote sensing, the total signal received (in VIS-NIR) at the satellite altitude is dominated by radiance contribution through atmospheric scattering processes and only $8-10 \%$ of the signal corresponds to oceanic reflectance. Therefore, it becomes mandatory to correct for atmospheric effect before retrieving any useful information from space.

The Top of the Atmosphere (TOA) radiance in OCM channel seven $(765 \mathrm{~nm})$ and eight $(865 \mathrm{~nm})$, mainly corresponds to contributions coming from the atmosphere, since water leaving radiance $L_{w}$ (765 and $865 \mathrm{~nm}$ ) can safely be assumed to be zero (Gordon and Clark 1981). An exponential relationship for the spectral behaviour of aerosol optical depth has been used in the atmospheric correction algorithm. A relationship has been obtained for the spectral behaviour of the aerosol optical depth using channels $765 \mathrm{~nm}$ and $865 \mathrm{~nm}$ of OCM data. The aerosol optical thickness has been extrapolated to visible channels using this exponential relationship. The OCM data were analysed using the atmospheric correction and bio-optical algorithms developed initially for IRS-P3 MOS data (Mohan et al 1998) and later modified for IRS-P4 OCM data (Chauhan et al 2001).

A sensitivity analysis was carried out on the OCM algorithm to study the changes in the retrieval accuracy of total suspended sediment concentration (SSC) due to errors in the OCM sensor detected radiances, choice of aerosol optical depth model (in the atmospheric correction procedure) and variability in the atmospheric ozone content and differences between the OCM band wavelengths and the wavelengths actually required for the estimation of SSC (SAC Technical Report 2000). This sensitivity analysis shows that for SSC detection with an accuracy of $30 \%$, the tolerable percentage radiance errors in the OCM bands are less than 6.0, 5.0, 6.0, 3.5 and 6.0 in bands 4,5 , 6,7 and 8 , respectively. The percentage error in SSC estimation due to the wrong choice of aerosol optical depth model and differences in the central wavelengths and the band widths are less than 10.0 and 1.0 respectively. Percentage errors in SSC retrieval due to 10, 20 and $30 \%$ changes in ozone content are less than 1.0, 1.9 and 3.1 respectively. It is clear from the above discussion that accuracy of atmospheric correction procedures strongly influence retrieval of SSC required for the application of MCC technique. Figure 1 shows IRSP4 OCM images for January 13th and 15th, 2000 before atmospheric correction as false colour composite (left panels) and after atmospheric correction as suspended sediment concentration (right panels) maps over Dhamra estuary, north Bay of Bengal.

\subsection{Geometric correction}

The implementation of pattern matching technique requires careful geometric correction and coregistration of the successive images within an error limit of one pixel. A rotation between the images reduces the matching coherency and a translation shift reduces the matching accuracy. A two-stage approach was followed. First of all geometric correction was applied separately on individual data sets to remove image distortion and bring them to a standard geographic projection, with modified everest datum (i.e., a local geodetic datum, based on the everest spheroid that 

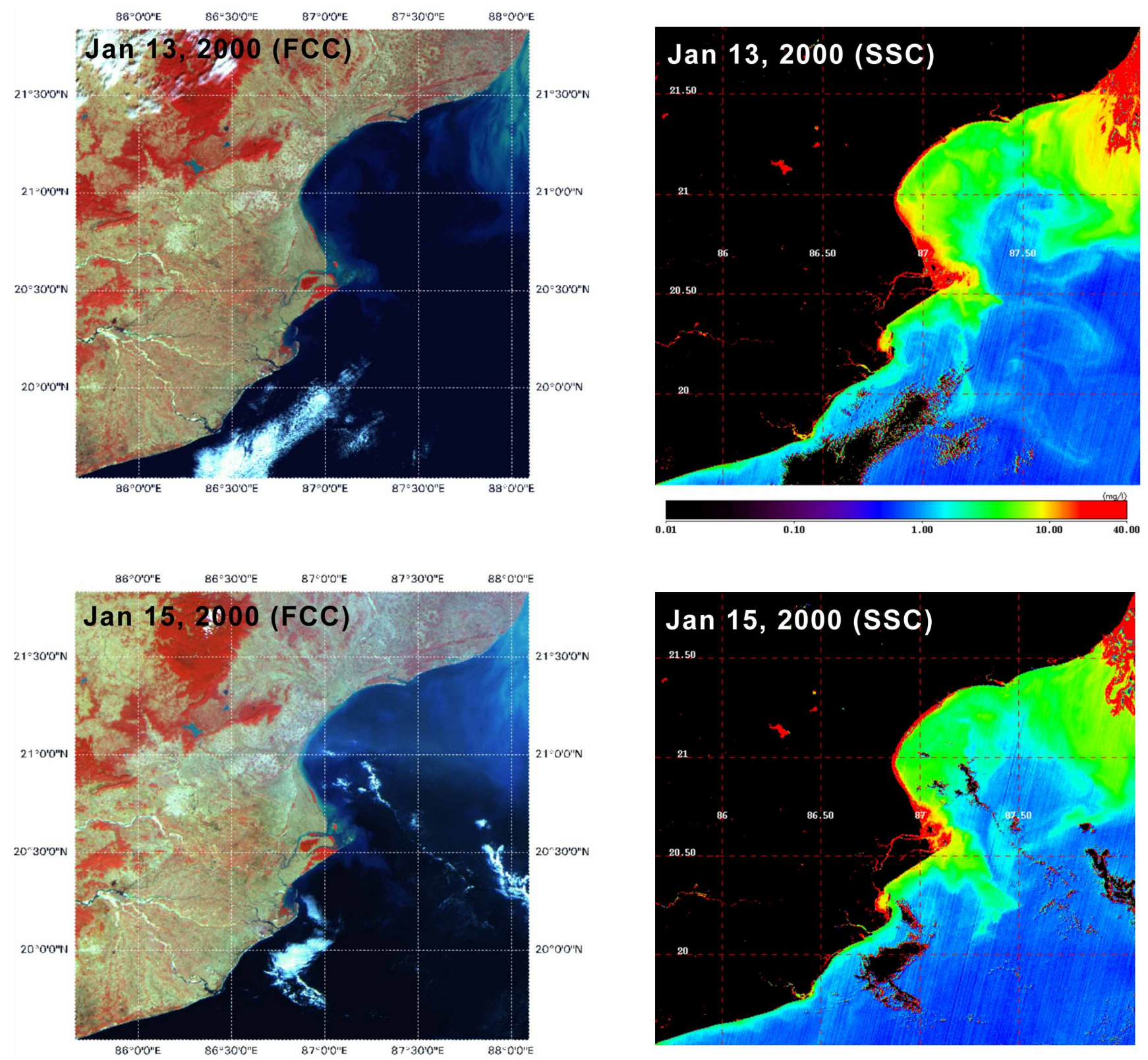

Figure 1. IRS-P4 OCM images for January 13th and 15th, 2000 before atmospheric correction are shown as false colour composite (left panels) and after atmospheric correction are shown as suspended sediment concentration (right panels) maps over Dhamra estuary, north Bay of Bengal. Note the distinct appearance of suspended sediments after atmospheric correction.

best fits the extent of the Indian subcontinent). In the second stage co-registration was done by warping one image to the other using polynomial transformation. The transformation was defined by matching more than 25 pairs (as many as possible) of Ground Control Points (GCP) on the images, selected from identifiable coastline features surrounding the area under study. The resampling at both the stages was performed by cubic convolution interpolation techniques to keep the spatial distortions at a minimum (Legeckis and Pitchard 1976; Emery and Ikeda 1984). The pair of the images could be co-registered within an error limit of one pixel (here 360 meters).

\subsection{Retrieval of suspended sediments}

The suspended sediment concentrations in the coastal areas have been derived using water-leaving radiance in band 490, 555 and $670 \mathrm{~nm}$. The algorithm initially proposed by Tassan (1994) has been used to compute suspended sediments from OCM data. It has the following mathematical form:

$$
\log S=1.83+1.26\left(\log X_{s}\right) \text { for } 0.0 \leq S \leq 40.0
$$

where $S$ is suspended sediment concentration in $\mathrm{mg} / \mathrm{l}$ and $X_{s}$ is the variable defined as 


$$
X_{s}=[\operatorname{Rrs}(555)+\operatorname{Rrs}(670)] \times\left[\frac{\operatorname{Rrs}(490)}{\operatorname{Rrs}(555)}\right]^{-0.5}
$$

where $\operatorname{Rrs}(\lambda)$ is the spectral remote sensing reflectance in respective wavelengths. The retrieval accuracy of SSC from OCM data is within 15\% (Chauhan 2002).

\subsection{Implementation of the Maximum Cross-Correlation (MCC) pattern matching technique}

The Maximum Cross Correlation (MCC) pattern matching method is based on calculating crosscorrelation coefficients (Emery et al 1986; Kamachi 1989; Gao and Lythe 1998). Statistically crosscorrelation is a measure of the linear relation of two random variables. The cross-correlation coefficient is given by Kreyszig (1970)

$$
\rho=\frac{\operatorname{cov}(x, y)}{\sqrt{\operatorname{var}(x) \operatorname{var}(y)}}
$$

where $x$ and $y$ represent random variables from a two-dimensional population, and var, cov are the variance and covariance of the random variables. By definition $-1 \leq \rho \leq 1$.

The computation method for deriving sea surface advective velocities consists essentially of identifying the maximum cross-correlation in a lagged matrix between two sub areas of a pair of sequential scenes. The first image is divided into continuous sub areas called template window. The size of this window is taken as $64 \times 64$ pixels. For the template, a large search window was identified in the second image, having the template as its centre. In the Cartesian coordinate system $f(x, y)$ and $g(x+p, y+q)$ denote a possible pair of similar patterns in two time lapsed images. The vector $(p, q)$ represents a possible spatial displacement of the original pattern between the two images. The crosscorrelation matrix is formed as (Wu et al 1992):

$$
\rho(p, q)=\frac{\operatorname{cov}\{f(x, y), g(x+p, y+q)\}}{\sqrt{\{\operatorname{var}[f(x, y)] \operatorname{var}[g(x+p, y+q)]\}}} .
$$

Since the computation of the cross-correlation matrix is time consuming, a significant reduction of computational effort can be achieved by working in the frequency domain using the Fast Fourier Transform (FFT) techniques. Use of the FFT has its limitations. It restricts one to square regions or at least rectangular regions. It is fast but requires integral length of the data series thus avoiding any irregularities due to cloud cover, coastline etc.
Using the procedure given by Leese et al (1971) and Ninnis et al (1986) for FFT, cross-correlation coefficients, between the template and searching kernels are calculated. For $128 \times 128$ search window and $64 \times 64$ template window, a matrix of $65 \times 65$ cross-correlation coefficients are calculated. From this matrix, maximum cross-correlation coefficient and corresponding $x$ lag $(p \max ), y$ lag $(q \max )$ are found. Figure 2 shows the schematic of feature tracking using the above approach.

The MCC method indicates the actual flow during a specific period (average of two-time lapsed images), i.e., integrating tidal and wind influences.

The maximum cross-correlation in the relative displacement $(p, q)$ between the template and the search windows of the sequential scenes determines the advective velocity vector; the magnitude of which is given by Garcia and Robinson (1989) as:

$$
C=\frac{\sqrt{(p \max \Delta x)^{2}+(q \max \Delta y)^{2}}}{\Delta t},
$$

and the direction of motion, $\theta$, can be calculated as

$$
\theta=\arctan \left[\frac{q \max \Delta y}{p \max \Delta x}\right]
$$

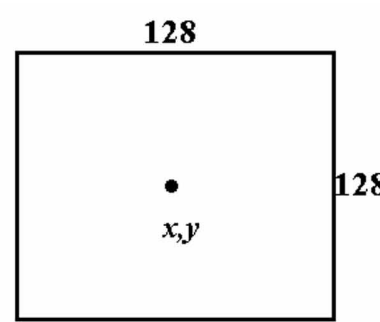

Search window

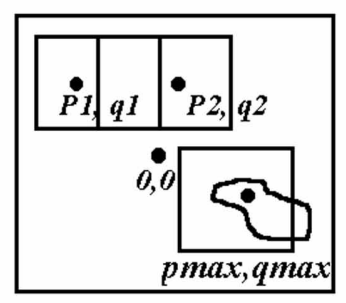

$x 1, y 1=x+p \max , y+q \max$

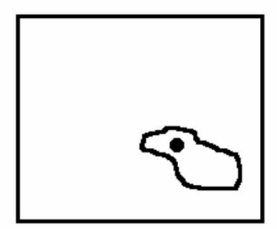

64

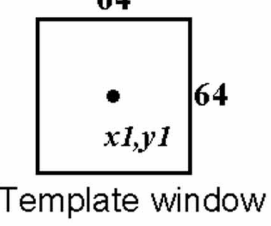

Template window

Template window

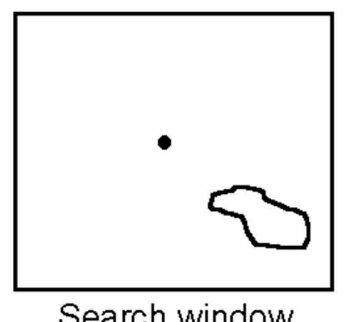

Search window

Figure 2. A schematic of the use of maximum cross-correlation technique for pattern matching. 


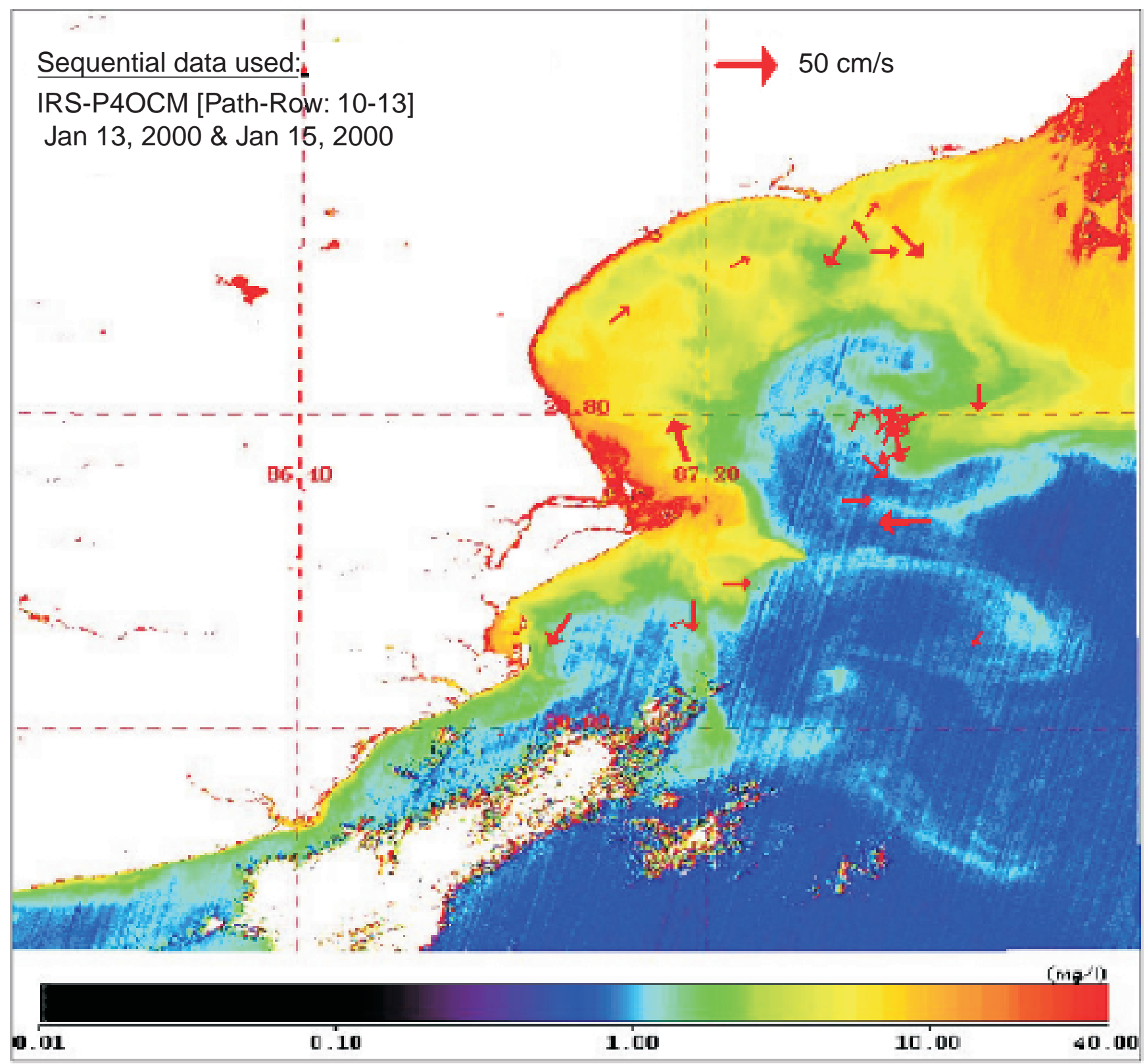

Figure 3. Advective sea surface velocities derived from sequential IRS-P4 OCM suspended sediment imageries (January 13 th and 15th, 2000) over Dhamra estuary, north Bay of Bengal.

\section{Results and discussions}

The patterns of ocean colour on sequential images are used as tracers to measure displacements of surface waters. The velocity derived, as a measure of this transport is known as the advective velocity. The spatial resolution was one of the major constraints for achieving the desired accuracy (Garcia and Robinson 1989; Wu et al 1992). IRS-P4 OCM data has improved spatial resolution and distinct signatures of suspended sediments acting as tracer and hence they were analysed to derive the advective velocities. Figure 3 shows the velocity vectors overlaid on suspended sediment concentration map derived from IRS-P4 OCM data of January 13th, 2000. The current velocities retrieved were compared with simultaneous data collected along the east coast of India. The current data were measured using ocean current meter supplied by the Environmental Measurement and CONtrol (EMCON), Kochi; available with the Geological Survey of India, Marine Wing. This current meter can measure direction and magnitude with an accuracy of $\pm 5^{\circ}$ and $2 \%$ respectively. The resultant magnitude and direction were calculated by averaging 10 and 50 readings respec- 
Table 1. Comparison of in situ current vectors and advective velocity vectors derived by maximum cross-correlation pattern matching method applied on sequential (January 13th and 15th, 2000) IRS-P4 OCM data covering north Bay of Bengal.

\begin{tabular}{|c|c|c|c|c|c|c|}
\hline Sr. No. & $\begin{array}{c}\text { Latitude } \\
\left({ }^{\circ} \mathrm{N}\right)\end{array}$ & $\begin{array}{c}\text { Longitude } \\
\left({ }^{\circ} \mathrm{E}\right)\end{array}$ & $\begin{array}{c}\text { In situ } \\
\text { magnitude } \\
\left(\mathrm{cm} \cdot \mathrm{s}^{-1}\right)\end{array}$ & $\begin{array}{c}\text { Derived } \\
\text { magnitude } \\
\left(\mathrm{cm} \cdot \mathrm{s}^{-1}\right)\end{array}$ & $\begin{array}{c}\text { In situ } \\
\text { direction } \\
\left(^{\circ}\right)\end{array}$ & $\begin{array}{c}\text { Derived } \\
\text { direction } \\
\left({ }^{\circ}\right)\end{array}$ \\
\hline 1. & 19.05 & 85.47 & 6 & 9.5 & 195 & 210 \\
\hline 2. & 20.97 & 87.16 & 12 & 10.0 & 312 & 288 \\
\hline 3. & 20.02 & 87.21 & 10 & 12.0 & 71 & 84 \\
\hline 4. & 21.07 & 87.16 & 15 & 13.5 & 185 & 172 \\
\hline 5. & 20.83 & 87.21 & 15 & 13.6 & 60 & 65 \\
\hline 6. & 20.97 & 87.26 & 16 & 15.9 & 73 & 75 \\
\hline 7. & 21.07 & 87.26 & 16 & 17.5 & 217 & 216 \\
\hline 8. & 20.91 & 87.26 & 20 & 18.6 & 253 & 278 \\
\hline 9. & 20.97 & 87.31 & 23 & 21.9 & 45 & 45 \\
\hline 10. & 20.71 & 87.31 & 26 & 23.9 & 255 & 280 \\
\hline 11. & 20.91 & 87.31 & 22 & 23.9 & 330 & 338 \\
\hline 12. & 21.08 & 87.21 & 24 & 25.0 & 193 & 188 \\
\hline 13. & 20.96 & 87.21 & 28 & 28.2 & 50 & 47 \\
\hline 14. & 19.12 & 85.60 & 35 & 29.4 & 260 & 270 \\
\hline 15. & 20.66 & 87.28 & 29 & 32.6 & 200 & 205 \\
\hline 16. & 20.97 & 87.36 & 41 & 39.8 & 216 & 208 \\
\hline 17. & 20.02 & 87.36 & 46 & 48 & 178 & 181 \\
\hline
\end{tabular}

tively up to $5 \mathrm{~m}$ depth during the IRS-P4 OCM pass time (around 12 noon) for each location
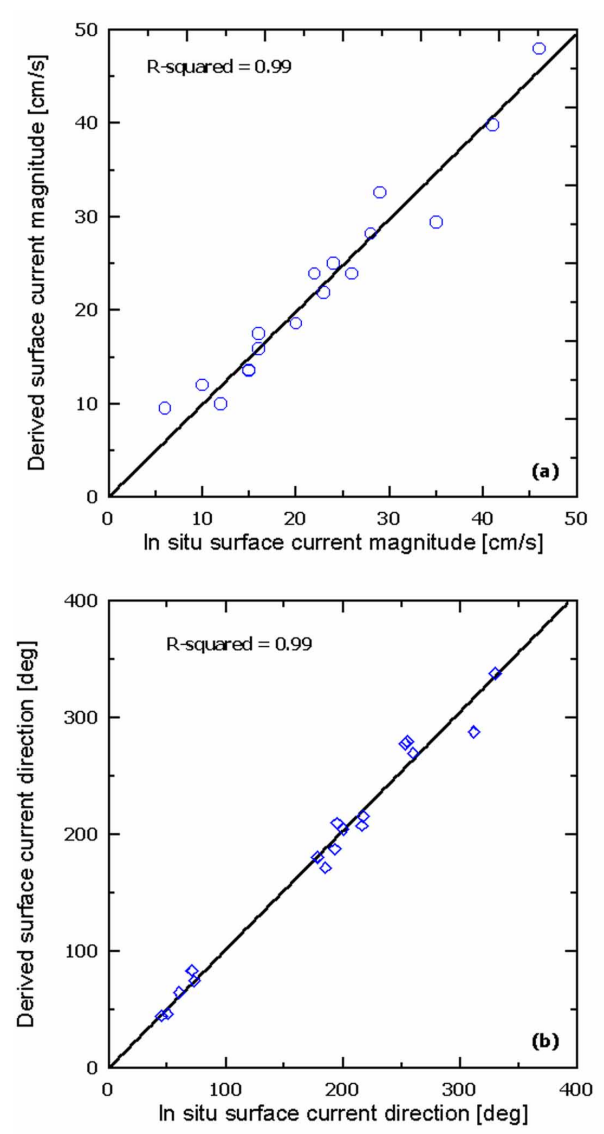

Figure 4. A plot of in situ surface current magnitudes vs the derived current magnitudes (a) and a plot of in situ surface current directions vs the derived surface current directions (b). used in this study. The Global Positioning System (GPS) of the ship was used for the geographical location measurements, whose accuracy is within meters far within the threshold location accuracy of around $1 \mathrm{~km}$ for OCM standard data products. The pair of the images could be co-registered within an error limit of one pixel (here 360 meters). Table 1 shows the in situ current vectors (13th and 15th January, 2000 off Dhamra estuary, north Bay of Bengal) and the advective velocity vectors derived by maximum cross-correlation pattern matching method applied on sequential (January 13th and 15th, 2000) IRS-P4 OCM data. The coefficient of determination, R-squared is 0.99 for both magnitude (in $\mathrm{cm} \mathrm{s}^{-1}$ ) and direction (in deg.) (figure 4).

This study demonstrates the feasibility of applying the maximum cross-correlation method to sequential IRS-P4 OCM data in order to generate vector fields representing the transport velocity of optically visible near-surface tracers.

\section{Acknowledgements}

The authors express their sincere gratitude to Dr. A K S Gopalan, Director SAC and Dr. R R Navalgund, presently, Director, NRSA, Hyderabad and earlier Deputy Director, RESA, SAC for their guidance and valuable suggestions during the course of this study. They are also thankful to Dr. N Sengupta, the then Deputy Director General, Marine Wing, Geological Survey of India for providing the opportunity to collect sea truth data during R.V. Samudra Kaustubh Cruise 
ST-133. Thanks are also due to the two anonymous reviewers for their constructive comments which have greatly improved the presentation of this work.

\section{References}

Chauhan P, Nagur C R C, Mohan M, Nayak S R and Navalgund R R 2001 Surface chlorophyll- $a$ distribution in the Arabian Sea and Bay of Bengal using IRS-P4 Ocean Colour Monitor satellite data; Current Science $\mathbf{8 0}$ $2127-129$

Chauhan, P. 2002 Personal Communication.

Emery W J, Thomas A C, Collins M J, Crawford W $\mathrm{R}$ and Mackas D L 1986 An objective method for computing advective surface velocities from sequential infrared satellite images; J. Geophys. Res. 91 C11 $12865-12878$

Emery W J and Ikeda M 1984 A comparison of geometric correction methods for AVHRR imagery; Can. J. Remote Sensing 10, 46-56

Gao J and Lythe M B 1998 Effectiveness of the MCC method in detecting oceanic circulation patterns at a local scale from sequential AVHRR images; Photogrammetric Engineering 83 Remote Sensing 64 4 301-308

Garcia C A E and Robinson I S 1989 Sea surface velocities in shallow seas extracted from sequential Coastal Zone Colour Scanner Satellite Data, J. Geophys. Res. 94 C9 12681-12691

Gordon H R and Clark D K 1981 Clear water radiances for atmospheric correction of Coastal Zone Color Scanner imagery, Appl. Optics 20 4175-4180

Kamachi M 1989 Advective surface velocities derived from sequential images for rotational flow field: Limitations and applications of Maximum Cross Correlation method with rotational registration, J. Geophys. Res. 94 C12 $18227-18233$
Kelly K A 1989 An inverse model for near-surface velocity from infrared images; J. Physical Oceanography 19 550-565

Kreyszig, Erwin 1970 Introductory Mathematical Statistics: Principles and Methods, (New York: John Wiley)

La Violette P E 1984 The advection of submesoscale thermal features in the Alboran sea gyro; J. Physical Oceanography 14 550-565

Leese J A, Novak C S and Clarke B B 1971 An automated technique for obtaining cloud motion from geosynchronous satellite data using cross-correlation; $J$. Appl. Meteorol. 10 110-132

Legeckis R and Pitchard J 1976 Algorithm for correcting the AVHRR imagery for geometric distortions due to the Earth curvature, Earth rotation and spacecraft roll attitude errors; NOAA Tech. Memo. NESS $\mathbf{7 7}$

Mohan M, Chauhan P, Mathur A and Dwivedi R M 1998 Atmospheric correction of MOS-B data using long wavelength and PCI approaches: IRS-P3 MOS validation experiment: Ocean Applications, SAC Report No. SAC/RESA/MWRD/IRSP3/SN/02/98, pp. 14-22

Ninnis R M, Emery W J and Collins M J 1986 Automated extraction of pack ice motion from advanced very high resolution radiometer imagery, J. Geophys. Res. 91 10725-10734

SAC Technical Report 2000 Test and evaluation report on IRS-P4 OCM special product generation software, Report No. IRS-P4/SAC/RESA/MWRD/TR/12/2000, p. 29

Tassan S 1994 Local algorithm using SeaWiFS data for retrieval of phytoplankton pigment, suspended sediments and yellow substance in coastal waters; Appl. Opt. 12 $2369-2378$

Vastano A C and Borders S E 1984 Sea surface motion over an anticyclonic eddy on the Oyashio Front; Remote Sensing Environment 16 87-90

Wu Q X, Pariman D, McNeil S J and Barnes E J 1992 Computing advective velocities from satellite images of sea surface temperature; IEEE Transactions On Geoscience and Remote Sensing 301 pp. 166-175 